Journal Home Page:

http://perlinguam.journals.ac.za

\section{Per Linguam}

A Journal for Language Learning Tydskrif vir Taalaanleer

\title{
ETHNO-LINGUISTICALLY DIVERSE SOUTH AFRICAN STUDENTS' WRITING
}

Verbra Pfeiffer \& Christa van der Walt

University of Stellenbosch

One of the major challenges for designers of academic literacy programmes is to accommodate culturally and linguistically diverse student groups. This longitudinal study was conducted with pre-service teachers at Stellenbosch University to determine their understanding of the importance of good writing and ways in which they can use translanguaging to assist them in their writing. This study has also been viewed against the backdrop of multilingualism in South Africa, with the notion of socio-cognitive processes and its influence on the students' ability to write. The aim of this study was to explore what students regard as good writing and to identify the kinds of strategies that multilingual students use when they write extended texts. When pondering on the holistic view of the findings, this study endorses the use of home languages in the educational practice of academic writing, but with particular caveats. The findings reveal that academic writing entails more than mere grammatical correctness on a surface level, but also involves taking cognisance of the second language learners' background and way of implementing mental structures derived from their home language.

Keywords: academic literacy, multilingual writing, biliteracy, translanguaging

\section{POINT OF DEPARTURE}

We acknowledge that the 'use of English' (Dearden, 2015: 2) can be operationalised to teach academic subjects where the majority of the population is not English. This could include 'sole use, partial use, code-switching and so on' (Macaro \& Akinciaglu, 2018: 256). Today it appears that, in most countries of the world, multilingualism is the norm rather than the exception (Carstens, 2018; Cummins, 2000; Heugh \& Skutnabb-Kangas, 2010). What this implies is that higher education classrooms are increasingly linguistically diverse.

Students collaboratively establish a 'translanguaging space' (Li, 2011: 1222), which can be thought of as a social space where they can draw on their linguistic resources and experiences of writing practices (Kaufhold, 2018: 1). In this study, we looked at ways in which the use of translanguaging affects writing skills of English first additional language students. Translanguaging may be viewed as a 'planned and systematic use of two languages for teaching and learning inside the same lesson' (Lewis, Jones \& Baker, 2012: 643) to facilitate understanding, second language (L2) learning, and first language (L1) development. In this article, we focus on the value of improving writing skills and the extent to which translanguaging occurs when students write in one language and think in another.

Learning to write in English, whether it is one's first, second or third language, continues to be a major educational venture throughout the world. According to Freedman, Pringle and Yalden (2014: 3), in the L2 context, the difficulties involved in learning combined with the 
difficulties in learning to write in one's own language at a level beyond that of minimal literacy are added to all the further complexities inherent in trying to master an L2. It is no longer only a matter of trying to master a different medium and learning how to handle its special exigencies; 'it is also a matter of learning how to express oneself appropriately in a different language and in a different culture' (Freedman et al., 2014: 3). Van der Walt (2016: 2) argues that language practitioners feel the need to develop mechanisms to solve the 'problem' of students who lack English-language proficiency by requiring a specific score on access tests, or by making courses in academic literacy or English for academic purposes compulsory. With this purpose in mind, in this article we look at how L2/L3 learners express themselves in the language of learning.

Carstens (2016: 2) argues that South African university students display a wide range of English proficiencies, as a small minority are mother-tongue speakers of English. Some studied English as a subject for 12 years (primarily mother-tongue speakers of Afrikaans). Some received tuition from grade 4 through the medium of English (the majority of black South African students taught at public schools in rural and township areas), while a number of L2 speakers graduated from private English-medium high schools and are well prepared for university study using English as medium of instruction. Therefore, through their extensive exposure to English throughout their schooling career, students have come to realise the importance of being proficient in English. It should be borne in mind that English is 'not the alpha and omega, which does not necessarily mean avoidance or loss of other languages' (Klapwijk \& Van der Walt, 2015: 3). Since English is not the home language for many students, this study sought to find out what role students' home or community languages may play in their writing.

Our universities' classes have become linguistically diverse and our academic literacy lecturers themselves display a variety of 'linguistic repertoires' (Carstens, 2016: 1). This links with Carstens's (2016: 2) view that, despite the worldwide trend to embrace multilingualism, an important consideration is whether to allow only the target language (English in the South African context) in the academic literacy classroom, or to create an environment for students to draw on their L1 or dominant language as social, linguistic and cognitive resource. As a result, we view writing as a manifestation of a multilingual repertoire. Accordingly, the multilingual nature of South African classrooms requires students to be able to describe what they regard as good writing to show that they are aware of the importance of developing this skill. Thus, we gathered students' opinions of what they thought good writing may be.

\section{LITERATURE FRAMEWORK}

Writing is central to postgraduate research, irrespective of the discipline (Vivian \& Fourie, 2016: 147). According to Cameron, Nairn and Higgins (2009: 269), 'writing is the foundation of an academic year'. Coffin, Curry, Goodman, Hewings, Lillis and Swann (2003: 2) argue that students' writing is often at the centre of teaching and learning in higher education, 'fulfilling a range of purposes according to the various contexts in which it occurs'. Coffin et al. (2003:2) further argue that students' writing relates to assessment ('the major purpose for student writing'), learning ('which can help students grapple with disciplinary knowledge') and entering particular disciplinary communities ("whose communication norms are the primary means by which academics transmit and evaluate ideas'). At postgraduate level, there is an entrance into important discipline-specific academic communities; it is primarily through certain writing activities that access to these disciplinary communities is granted 
(Vivian \& Fourie, 2016:147). Indeed, students are familiar with their discipline-specific terminology in their fields, which is in the medium of instruction (English/Afrikaans/IsiXhosa). However, we wanted to make students aware of their home language and ways to use it as an advantage in academic writing.

English remains the primary medium of instruction, and students may use their L1s as auxiliary mediums of learning (Carstens, 2016; Madiba, 2013: 394). In situations where a former colonial language is the medium of instruction, minority languages are often regarded as a problem (Ramani, Kekana \& Madiba, 2007: 208). In this article, we look at issues and problems that students identify as influencing their writing.

According to Rohamn (1965: 107-108), 'good writing' involves the discovery of a combination of words which allow a person to act with integrity and to dominate his or her subject with a fresh and innovative pattern. He continues to say that 'bad writing', then, is an echo of someone else's combination, which a person has merely taken over for the occasion of his or her writing (Rohamn, 1965: 108). In light of this, 'good writing' may be viewed as a path where a responsible person may discover his or her uniqueness in his or her subject. In this article, we address students' understanding of good writing and the use of words that dominate their subject.

Fulkerson (1996: 74) addresses four terms which he associates with good writing: a formalist perspective that embraces correct and well-organised writing; a mimeticist perspective that proposes factual correctness in content; an expressivist perspective that emphasises sincerity, heartfeltness, honesty, authenticity or originality of voice; and a rhetorical perspective that persuades, engages or interests its audience. We suggest that the variety of composition terms Fulkerson (1996) uses to talk about 'good writing' can help us clarify the assumptions which creative writing teachers employ to assess growth and development in their students. Hence, students should learn that 'bad writing is part of the process of doing good writing' (DeLyser, 2003: 170-172). In addition, good writing is good dialogue - always mixing, changing, incorporating, answering, anticipating, and merging the writer and the reader in the construction of meaning (Middendorf, 1992; DeLyser, 2003:172).

In a bi- or multilingual education context where students are presented with lectures and study material in more than one language, students are allowed to exploit their bi- or multilingual proficiency without focusing on one language only (Van der Walt \& Dornbrack, 2011). Thus, academic language proficiency requires high levels of writing fluency in English. The focus of this paper is to determine what students and prospective English language teachers regard as good writing, in the context of a multilingual country.

Translanguaging seeks to assist multilingual speakers in making meaning, shaping experiences, and gaining deeper understandings and knowledge of the languages in use and even of the content that is being taught (Cenoz \& Gorter, 2011; Lewis, Jones, \& Baker, 2012; Sun Park, 2013; Williams, 2002). Carstens (2016: 205) defines 'translanguaging' as one of the strategies that holds potential for both supporting the language-as-a-resource intention by empowering students to become proficient in the medium of instruction and occupying the niches that governmental and institutional policies have created for scientific meaning-making through students' strongest languages. The term translanguaging has been stressed as the flexible and meaningful actions through which bilinguals select features in their linguistic repertoire in order to communicate appropriately (Valesco \& Garcia, 2014). Translanguaging has also been viewed as helping us to adopt orientations specific to multilinguals and 
appreciate their competence in their own terms (Canagarajah, 2015). Nevertheless, in this context we view translanguaging in writing as a self-regulating mechanism in which bi- or multilingual students can engage, rather than a pedagogy to be used in the teaching of writing itself (Velasco \& Garcia, 2014). What this implies is that the communicators' entire 'semiotic repertoire' is present at all times, and they simultaneously draw upon different sets of language features (grammar, lexis, phonetics) from different languages or other semiotic systems (Carstens, 2016: 206).

Learning to write is not just a question of developing a set of mechanical 'orthographic' skills; it also involves learning a new set of cognitive and social relations (Tribble, 1996; Pfeiffer, 2015). Writing alone is typically grounded in the cognitive processes such as planning, translating, and reviewing or revising, rather than on the levels of language involved in translating ideas into a written product (Abbott, Berninger \& Fayol, 2012).

\section{METHODOLOGY}

In three successive years (2016-2018), we polled Postgraduate Certificate in Education (PGCE) students from a South African university by giving them the opportunity to respond in writing to four open-ended questions:

1. What is good writing and why is it important to develop that ability?

2. A question to English first additional language students: Do you use your home language when you write? If so, how do you do it?

3. When does writing in English become challenging for you?

4. What is the most challenging part of writing for you (home language and first additional language)?

The students were polled in the first semester and again in the second semester, when their responses were handed back to them and they were asked to indicate whether their perceptions of 'good writing' had changed since their practical training in schools. For the purposes of this article, we do not report on this aspect of the study, because we have not collected the 2018 second semester data yet.

The paradigm of this study was an interpretive discourse analytical perspective. To analyse the data, we used a three-tiered analytic process as suggested by Miles and Huberman (1994: 92):

- prepare the data sets and check for completeness;

- analyse the information and identify themes and categories; and

- synthesise the data by abstracting possible trends and linking the data to other research insights.

The trustworthiness of the process was strengthened by the two authors doing the analysis individually and then checking each other's categorisations. It became clear to us that certain words and phrases were repeated, and we decided to strengthen our analysis by using word counts. This strategy was useful to check for inconsistencies in our analysis and it also helped us to not miss anything in the wealth of data. By the third year, however, we realised that this strategy could result in us missing particular themes because we were only looking for those that we knew had appeared in the earlier data. To overcome this problem, we only did the 
word searches after our initial reading of the data. This process meant that we identified new themes, which meant that we went back to the earlier data to analyse those responses again.

The word counts not only strengthened the trustworthiness of the data, but also showed the variability across the three years. In response to the question about what students thought good writing was, the idea of 'flow' (e.g., sentences or ideas 'flow') as well as 'cohesion/ coherence/ cohesive(ness)' appeared repeatedly in the data of the first two years. However, in the third year, when we had the largest group of responses, these words and phrases were not as numerous (Table 1).

Table 1: Variability of word counts over three years

\begin{tabular}{|l|l|l|l|}
\hline Words/phrases & Years & \\
\hline & $2016(\mathrm{n}=62)$ & $2017(\mathrm{n}=74)$ & $\begin{array}{l}2018 \quad(\mathrm{n} \\
243)\end{array}$ \\
\hline Flow (e.g., sentences or ideas 'flow') & 35 & 14 & 17 \\
\hline Cohesion/ coherence/ cohesive(ness) & 26 & 25 & 16 \\
\hline
\end{tabular}

This comparison showed the degree to which conceptions are fleeting and may be influenced by a variety of factors, such as (possibly) the type of students who volunteered to respond. Since the responses were anonymised, we do not know, for example, whether students who majored in language teaching dominated the first groups.

In the discussion that follows, it is important to keep in mind that the word counts served to strengthen our initial analyses; they did not determine the coding process.

Ethical clearance was obtained from the university.

\section{RESULTS}

In the discussion that follows, the focus is on the first three questions, mainly in an effort to show what students valued in writing and how they used their home or community languages to support their own writing. We hope to show that the focus of the students on particular features of 'good writing' may have had an influence on how they utilised their home languages for academic writing (in English) in particular. We use italics to indicate students' words which have not been corrected or adapted in any way.

\section{Themes from question 1}

The question 'What is good writing?' was deliberately formulated in this way to get a wide variety of responses. We were not interested only in academic writing or creative writing or L2 writing. In fact, some students made specific distinctions in their responses, for example by saying 'I also feel that good writing is not necessarily academic writing.' It was therefore interesting that the first theme mentioned below was by far the most dominant theme across the three years.

\section{Theme 1: A focus on surface features and language mechanics}

Across the data sets, students emphasised surface features of correctness and what one could call the 'mechanics' of writing, such as spelling and punctuation. However, the words '(in)correct(ly)' were used mostly with the concept of grammar: 
Good writing [...] also includes the correct and accurate use of grammar and punctuation.

You need to be able to use the correct vocabulary words and correct form of grammar.

It also includes the use of the correct punctuation and spelling of words.

The words 'accurate' and 'accuracy' were used rarely, but when they were, they linked up with the issue of correctness:

Good writing is characterised by good diction and grammar that allows accurate presentation of thoughts.

In the 2018 data, a few references to accuracy linked to the author providing information, for example:

... to convey information accurately and in a medium that the reader can understand.

These last two statements went further than correctness of particular features of language: they constituted a link between accuracy and the degree to which a text is understood. This strand in our data linked up with correctness, but in a more complex manner, particularly if the students were thinking about academic writing.

Theme 2: The 'transparency' of language

The link between accuracy or correctness and comprehension was expressed mostly in statements about the clarity of language use, or the invocation that language should be used 'clearly' to 'make sense', with the result that the reader will understand:

Good writing commit of conveying a message clear so that the person who reads the writing understands what is being said.

The phrase 'clear and concise' appeared regularly, particularly in the 2018 and 2017 data. In the 2016 data, 'concise' appeared 15 times with the word 'coherent'.

For some students, clarity of thought was the responsibility of the author and a precondition for understanding:

Good writing is when you have a clear understanding of the topic that you are writing about.

Good writing is when the writer can clearly state his/her thoughts and arguments.

The same idea could be found when 'clear' was used as a verb:

... your way of expressing yourself help to clear out the misunderstandings in writing.

The idea that there is one, clear understanding of a text or concept is described by Hyland (2013: 58) as 'the familiar CONDUIT METAPHOR of language, which suggests that others are able to recover our thoughts from our words exactly as we intended.' Although there is an awareness of audience (see discussion further on), this view of writing does not take the context in which texts are produced into account. More importantly, as the focus on correct 
grammar, spelling and punctuation shows, writing is seen as 'a set of discrete, value-free rules and technical skills' (Hyland, 2013: 58).

Clarity is also linked to the structure of writing and the way in which the text appears to be 'coherent'. However, from the way in which clarity and structure were used in the majority of the responses, these aspects function above sentence level, as the next theme shows.

\section{Theme 3: The way in which the structure of a written piece coheres}

For the students involved in this project, writing longer pieces of text seemed to be associated with academic writing, and for that reason, the quality of argumentation was an important indicator of 'good writing'. Two sub-themes emerged in this case: the importance of (i) structure and (ii) the coherence of a piece of well-structured writing. Although these two subthemes can be distinguished, they were often interlinked in the data, as the following excerpt shows (keywords underlined):

Good writing should convey a structured, well-thought-out argument or theme that is fluid and clearly depicted through writing.

The idea of correctness appeared in this theme as well:

Good writing is clear and in the correct order.

A 'correct order' also appeared in the guise of a 'logical' structure:

Good writing is writing a piece or text that makes sense logically-coherent.

... sentences should follow a logical sequence.

Conceptions of 'flow' and coherence' appeared as an important feature of good writing, sometimes separately and sometimes together. 'Flow' appeared to be linked to structure at and above sentence level:

... flowing from one sentence to the next.

Also, good writing is when the writer or your writing has structure or a good flow. Usually it consists of an introduction, a body and conclusion.

When linked to 'coherence' or 'cohesion', the construction of meaning was presented as a result:

Good writing is writing that is coherent, meaning that it is unified. It has to have flow so that reading is easy and natural.

... formulate sentences coherently and effectively.

In most of these extracts from the students' responses, it is clear that the possible impact and meaning of writing was foremost in their minds.

Theme 4: Commendable writing is the responsibility of the writer 
The fact that the question focused on commendable writing meant that the participants underscored the responsibility of writers to make themselves understood. In this case, references to 'writer' or 'author' were coupled with words like 'good', 'effectively', 'clearly', 'should' and 'must be able':

In practice it would be the skill and proper use of language-based rules and selfability to connect to a topic of writing, for the writer to fully express themselves clearly and the reader or recipient to clearly receive and understand the piece/story.

[Good writing is ...] When the writer is able to write and convey their message or idea in a fluent and readable manner.

An awareness of different aspects of the writing process was also mentioned in this theme:

- Awareness of audience:

As a writer you must be able to convey meaning in a way that accommodates the target audience.

- Awareness of different dialects and varieties of English was linked to awareness of audience:

[Commendable writing] also enables speakers with different dialects of a language, to understand what is being said.

... instead there are many englishes, all deserving of the title 'good English'. 'Good writing' then should be writing that is understandable to the intended audience.

- An awareness of genre was also closely linked to audience awareness:

Good creative writing is distinct from good advertisement writing for instance. to make use of a language in a correct way which could be academic or fiction.

Although correctness featured here too, the meaning seemed to be connected to the correct use of language according to the conventions of a particular genre.

Theme 5: Literary elements and creativity as signs of good writing

In contrast to the focus on academic writing, a small number of participants across the three years referred to creativity in writing, to the power of literature and the use of literary devices when writing:

Have you been transported to a world of imagination where fact and reality married fantasy? A journey with no inadequacy or limitations. A relationship between word, thought and expression flourishing. For me, that is good writing. Being able to understand it and read it improves this relationship.

Without creative plots, scenes and dialogue the writing will be classified as bad.

Nifty evocation of imagery. 
Good writing should demonstrate a level of creativity.

An eye-catching sentence or an artistic take on the piece of text.

In this case too, participants pointed to an awareness of genre:

... as the ideas one is trying to convey with a creative narrative will be very different from those one will attempt to convey with an academic argumentative essay.

As is clear from these five themes, participants had a range of ideas about what good writing was, and these ideas would naturally have been at the back of their minds when they responded to the question about whether they used their home or community language when they wrote.

\section{Themes from question 2}

One of the aims of this project was to raise awareness of the possibilities to use other languages as a resource when writing in English, mostly for academic purposes. Question 2 was therefore addressed at second language users of English in particular. We firstly tried to establish how many students actually used their home language when writing in English. Over the three years, the percentage of South African participants who used their home languages when writing English remained more or less stable, as Table 2 shows.

Table 2: Percentage of South African students who professed to use their home languages when writing in English

\begin{tabular}{|l|l|l|}
\hline $\mathbf{2 0 1 6}(\mathbf{n}=\mathbf{6 2})$ & $\mathbf{2 0 1 7}(\mathrm{n}=\mathbf{7 4})$ & $\mathbf{2 0 1 8}(\mathrm{n}=\mathbf{2 1 2})$ \\
\hline $22(35 \%)$ & $22(30 \%)$ & $63(30 \%)$ \\
\hline
\end{tabular}

Since English is used increasingly as the only language of learning and teaching at universities in South Africa and internationally, reference was made mostly to moving from the home language to English. The most common technique across the data sets was that of using translation. However, from the way in which students formulated their responses, this was not always a matter of direct or literal translations.

Theme 1: Using translation (also called 'reword' or 'convert' from one language to another)

In the data, most students who responded to this question were Afrikaans-English bilinguals, although there were isiXhosa students as well.

I read the sentence in english and try to reword it in Afrikaans (or figure out what it should be in Afrikaans) in order to get a better understanding of it. I will then re-write it in English.

For academic purposes, I use English, but I do make use of Afrikaans translations in my head, while writing.

In my language [isiXhosa] ... in order to make a point you must use a series of words, however when I think I think in my language and quickly translate into English. 
There was also an awareness that translation cannot be literal (underlining added):

I will say it in Afrikaans and then try to capture the spirit of it in English.

I often use metaphors from my home language to write in English or just translate them. The general idea is being able to express oneself (IsiXhosa).

The most widely used resource was the dictionary. Many participants referred to looking up words or getting stuck and then using their home language to look up words in a bilingual dictionary.

Theme 2: planning and structuring in the home language(s)

Some participants mentioned that they planned or structured sentences in their home language and then wrote in English. This use of the home language can be seen as a more conceptual engagement with the topic of the written text, rather than simply translating to English when getting stuck for a word.

I first get my thoughts together in Afrikaans...

I spend most of my time speaking isiXhosa and when I'm required to write anything in English, I first have to mentally prepare myself.

Some participants acknowledged that they did most of their thinking (for academic writing) in the home language:

I will always first structure my work in Afrikaans and do all my planning in Afrikaans. From there I will translate it to English, but most to all of my thinking and planning happens in Afrikaans.

If students have the ability to conceptualise in one language and then 'translate' into English (or whatever language they use for academic purposes), it can be argued that their 'depth of processing' (Knapp 2014: 30) may be enhanced to a greater extent than students who try to write in English from the beginning and then look up words when they become stuck.

Theme 3: Keeping languages apart

In step with conventional ideas of language learning, participants mentioned that they deliberately avoided the home language and that they tried to 'think in English'. It is interesting that they found it necessary to say that they did not use their home language when writing in English, and yet they still responded to the question about how they used their home languages. Students evaluated the use of another language when writing negatively:

Sometimes doing so can lead to unnecessary grammatical errors in writing.

Afrikaans is my home language, although I prefer learning and reading in English because it is a global language. When I write in English, I think in English.

The idea of 'thinking in English' was seen as evidence that the user is completely at home and fluent in the language, as these Afrikaans-speaking students argued:

Per Linguam 2019 35(2):58-73

http://dx.doi.org/10.5785/35-2-852 
I used to follow that pattern [translating from Afrikaans to English]. However, I've decided to immerse myself in the language completely and entirely in order to express myself eloquently in English. Completing my undergrad in English assisted this journey.

Not anymore, I used to use it in my first year. I always read the Afrikaans questions first and the English, just to be sure I understood. However, now I no longer read the Afrikaans, since it only confuses me.

Despite these monolingual views of writing occurring in our data, the majority of the students who chose to answer this question provided us with strategies that they clearly indicated to be working for them. The challenges of reading and writing academic texts were mentioned often as the reason for such strategies.

\section{DISCUSSION}

The dominant theme to emerge from responses to the first question was that of a focus on correctness, although students also highlighted flow and coherence, particularly in the 2016 and 2017 data sets. In contrast, strategies for using the home language were reported to serve as ways to think about, plan and structure their writing and dominated their responses to the second question, with smaller numbers referring to translations of words or using the dictionary to find a word in English. One could say that this is self-evident, since secondlanguage users of English will probably be concerned about the correctness of their writing, although one could still ask why this concern would dominate a question about the nature of good writing.

There are many possible answers to this question, and the most obvious could be that, in the first question, students were thinking of a completed text (rather than the action of writing), and in the second they were obviously concerned with the process of creating a text, as is clear from the question. However, we would like to argue that the answer could lie in the practices that students are exposed to when they write: the ways in which teachers and lecturers would point out relatively innocuous mistakes without engaging with the structure or coherence of their writing. The idea that writing should be clear and correct points to perceptions of writing as a unitary concept, as Hyland (2013:58) points out:

Writing is regarded as an autonomous system that we all understand and use in roughly the same way and that is transparent in reflecting meanings, as opposed to the way individuals negotiate and construct meaning. In this view, then, good writing is largely a matter of grammatical accuracy.

The fact that the use of the home language preceded writing in English and, in the case of translation activities, took place during writing in English, could say something about the peripheral and near-invisible nature of other languages when writing in English. In fact, some students wrote that they had never thought about whether they might be using their home languages while writing in English. If the home languages had a more explicit role to play in writing instruction, an awareness of how languages differ grammatically and orthographically might improve students' ability to check their grammar and spelling after writing, should this be seen as a priority. 
When a student writes, one student reported that: 'I spend most of my time speaking isiXhosa and when I'm required to write anything in English, I first have to mentally prepare myself.'

The effort is clear from the abovementioned quotations, since the participants reported that they needed time to think when using the second language. Although we agree with Hyland (2013: 68) that an academic lingua franca makes sense, we also have to heed his warning that 'there is a real danger this will exclude many L2 writers from the web of global scholarship.' Seeking solutions to these 'social inequalities of power' (Hyland, 2016: 21), the form of a multilingual pedagogy may prove problematic unless the status of the dominant language is challenged in a more critical view of academic literacy. Even then, as Canagarajah and Michael-Luna (2007: 71) have shown, students feel that they are asked to separate aspects of their identity from the academic sphere when home languages are limited to certain tasks; in this case to planning and translating words they cannot immediately access in English: '[The students] felt uncomfortable with the power difference this separation implied: though the vernacular was given a place in the school, it was secondary to mainstream discourses.'

The myth that it is easier to keep languages apart and to 'think' in English was seen in our data when students said, for example, that they were able to express themselves eloquently in English. More importantly, the avoidance of the home language was seen as a sign of progress when they pointed out that they did not have to translate anymore. Hyland (2013:68) reports on lecturers in his institution who did not want their colleagues to know that they were attending classes in academic writing, because 'not only does it [writing] have to be engaging, interesting and persuasive, it must also be effortless.' The consequences of this attitude in our study means that a pedagogy in which lecturers encourage students to use their home languages to enhance the depth of processing (Knapp 2014: 30) and improve conceptual understanding (Madiba, 2014: 99) will be perceived as reinforcing limited language proficiency in English.

When considering our data, we agree with Hyland's (2016: 39) argument that we can no longer regard a 'good writer' as someone who has control over the mechanics of grammar, syntax and punctuation, as in the autonomous view of writing, a 'good writer' is not someone who is able to mimic expert composing and 'knowledge-transforming' practices by reworking his or her ideas during writing, as in process models. Instead, 'we need to understand the full complexity of writing as a situated activity' (Hyland, 2013: 69) by introducing discussions around the perceived nature (clarity) and demands (correctness) of academic writing and the ways in which other languages can and should enter the rarefied air of academic writing in our contexts. Although the students in our study did show an awareness of genre, this was mostly a distinction between academic writing and literature, rather than different genres of academic writing as argued for by Hyland (2013).

The $30 \%$ of the students who used other languages when writing in English had clearly developed a range of strategies that worked for them if we take into account that they managed to get a first degree using them. They translanguaged by using 'their linguistic and experiential resources to achieve understanding' (Velasco \& Garcia, 2014: 21). Whether they plan and structure their writing in their home languages or try to reword a home language metaphor or image in English, we agree with Velasco and Garcia (2014:21) that they can, and do, self-regulate and advance their learning. In addition, effective language learning, including the effective use of translanguaging strategies, requires enactment within a meaningful context, as Hyland (2013: 69) points out, as it facilitates the processing of linguistic and writing demands (Velasco \& Garcia, 2014). 


\section{CONCLUSION}

The ultimate aim of this project was to motivate student teachers to see the importance of good writing so that they, as future teachers, can prepare the learners by improving their writing skills for when they enter university. Teachers need to be made aware that no one needs to be 'held hostage by language and culture' (Canagarajah, 2002: 68), and that learners should be taught to utilise their home language ability when they are writing in class. However, our results show that students focus on surface features like correct grammar and spelling and that, for the majority, the use of home languages does not seem important in the writing process. Students are typically required to adopt a style of writing at university which involves anonymising themselves and adopting the guise of a rational, disinterested, asocial seeker of truth (Hyland, 2016: 45). From the data, we can see that students develop very specific ideas about what makes writing 'good' and 'bad', ideas that have probably been formed at school already.

When students' major concerns are correctness of grammar, spelling and punctuation, and the clarity of their writing, it is clear that they subscribe to a view of writing as an almost mechanical skill where the language has one, clear meaning. More attention should be paid to developing fluency beyond sentence level in the form of argumentation and structuring of writing, which did not seem as important when students described good writing. Although there was an awareness of the difficulty of writing academic texts, the possibility of using another language to negotiate meaning was only exploited by a third of the students.

We need to recognise that the majority of students do not arrive at university with ready-touse academic skills, but rather develop these skills during the course of their time spent at the institution, and that an opportunity to reflect, talk through, read out aloud and discuss in their home language will facilitate the expression of academic concepts in English. This clearly surfaced in the student responses to question 2.

In the context of the university where this study was done, students are able to develop academic biliteracy and to use their languages in the powerful domain of higher education academic discourse, thereby 'open[ing] up implementation spaces for multiple languages, literacies, and identities in classroom, community, and society' (Hornberger, 2007: 188). In this context, the use of other languages is commonplace, which also means that, as a situated practice (Hyland, 2013: 69), a multilingual writing pedagogy has a good chance of success. As indicated by Van der Walt (2016: 10), using a variety of languages effectively is a teaching and learning issue - this is where multilingual classroom practices find their 'regulative' home.

The implications for pedagogy are that multilingual students can be encouraged more explicitly to draw on their other languages to get a task done in English. The focus on surface features is probably instilled by teachers and lecturers who find this an easy target for comment and revision, but it will not support students' ability to plan and structure their writing generally and in terms of academic demands specifically. What this means for teacher education is that prospective teachers need to be made aware of the negative consequences of marking surface features when they assess extended writing pieces at school level. Preparation for academic literacy development at higher education level is dependent on better preparation of student teachers to manage writing in a way that leads to fluency. 
Constructing a context in which students are encouraged to draw on their various languages (even if complete fluency is not available) as resources, rather than as barriers, benefits learning, and more emphasis on the local language enhances competence in the additional language, rather than detracting from the learning of an additional language (Brock-Utne, 1997; Van der Walt \& Dornbrack, 2011). We deduce that, rather than forming barriers for learning, the bilingual requirements of the context stimulated students to discover ways to negotiate writing tasks and, in Garcia's (2009: 45) words, 'translanguage to construct meaning.' It appears that the students were appropriating the language 'on their own terms, according to their needs, values and aspirations' (Canagarajah, 1999: 175-179). What we discovered is that some of the participants had the opportunity and enough confidence in their bilingual competence to use their mother tongue as an academic language (Van der Walt \& Dornbrack, 2011).

\section{REFERENCES}

ABBOTT, RD, VW BERNINGER \& M FOYAL. 2010. Longitudinal relationships of levels of language in writing and between writing and reading in grades 1 to 7 . Journal of Educational Psychology, 102:281-298.

BROCK-UTNE, B. 1997. The language question in Namibia. International Review of Education, 43(2/3):241-260.

CAMERON, J, K NAIRN \& J HIGGINS. 2009. Demystifying academic writing: reflections on emotions, know-how and academic identity. Journal of Geography in Higher Education, 33(2):269-284.

CANAGARAJAH, AS. 1999. Resisting linguistic imperialism in English teaching. Oxford: Oxford University Press.

CANAGARAJAH, AS. 2015. Corrigendum to 'Blessed in my own way: pedagogical affordances for dialogical voice construction in multilingual student writing'. Journal of Second Language Writing, 32:122-139.

CARSTENS, A. 2016. Translanguaging as a vehicle for L2 acquisition and L1 development: students' perceptions. Language Matters, 47(2):203-222.

CARSTENS, A. 2016. Desigining linguistically flexible scaffolding for subject specific academic literacy interventions. Per Linguam, 32(3):1-12.

CENOZ, J \& D GORTER. 2011. A holistic approach to multilingual education: introduction. Modern Language Journal, 95:339-343.

COFFIN, C, MJ CURRY, S GOODMAN, A HEWINGS, TM LILLIS \& J SWANN. 2003. Teaching academic writing: a toolkit for higher education. London: Routledge.

COLYAR, J. 2008. Becoming writing, becoming writers. Qualitative Inquiry, 15(2):421-436.

CUMMINS, J. 2000. Language, power and pedagogy: bilingual children in the crossfire. Buffalo, NY: Multilingual Matters.

DEARDEN, J. 2015. English as a medium of instruction: a growing global phenomenon. Available from http://www.britishcouncil.es/sites/default/files/british_council_english_as_a_medium_o f_instruction.pdf [Accessed: 11 September 2019].

DELYSER, D. 2003. Teaching graduate students to write: a seminar for thesis and dissertation writers. Journal of Geography in Higher Education, 27(2):169-181.

FREEDMAN, A, I PRINGLE \& J YALDEN. 2014. Learning to write: first/second language. In CN Candlin (Ed.), Applied linguistics and language study. New York: Routledge.

FULKERSON, R. 1996. Teaching the argument in writing. Urbanan, IL: NCTE.

GARCIA, O. 2009. Bilingual education in the 21st century: a global perspective. Malden, MA: Wiley/Blackwell.

Per Linguam 2019 35(2):58-73

http://dx.doi.org/10.5785/35-2-852 
GARCIA, O. 2011. From language garden to sustainable languaging: bilingual education in a global world. Perspectives, 34(1):5-9.

HEUGH, K \& T SKUTNABB-KANGAS (Eds). 2010. Multilingual education works: from the periphery to the centre. Delhi: Orient Blackswan.

HORNBERGER, N. 2007. Multilingual language policies and the continua of biliteracy: An ecological approach. In O Garcia \& C Baker (Eds), Bilingual education: an introductory reader. Clevedon: Multilingual Matters. 177-194.

HORNBERGER, N \& H LINK. 2012. Translanguaging and transnational literacies in multilingual classrooms: a biliteracy lens. International Journal of Bilingual Education and Bilingualism, 15:261-278.

HYLAND, K. 2013. Writing in the university: education, knowledge and reputation. Language Teaching, 46(1):53-70.

HYLAND, K. 2016. Teaching and researching writing. New York: Routledge.

KAUFHOLD, K. 2018. Creating translanguaging spaces in students' academic writing practices. Linguistics and Education, 45:1-9.

KLAPWIJK, N \& C VAN DER WALT. 2015. English-plus multilingualism as the new linguistic capital? Implications of university students' attitudes towards languages of instruction in a multilingual environment. Available from http://www.researchgate.net/publication/281026971 [Accessed: 19 September 2018]. 138.

KNAPP, A. 2014. Language choice and the construction of knowledge in higher education. European Journal of Applied Linguistics, 2(2):1-39.

LEWIS, G, B JONES \& C BAKER. 2012. Translanguaging: developing its conceptualisation and conceptualisation. Educational Research and Evaluation, 18:655-670.

LI, W. 2011. Moment analysis and translanguaging space: discursive construction of identities by multilingual Chinese youth in Britain. Journal of Pragmatics, 43(5):12221235 .

MACARO, E \& M AKINCIOGLU. 2018. Turkish university students' perceptions about English medium instruction: exploring year group, gender and university type as variables. Journal of Multilingual and Multilingual Developments, 39(3):256-270.

MADIBA, M. 2014. Promoting concept literacy through multilingual glossaries: a translanguaging approach. In L Hibbert and $\mathrm{C}$ van der Walt (Eds), Multilingual universities in South Africa. Bristol: Multilingual Matters. 68-87.

MAKONI, S. 2003. From misinvention to disinvention of language: multilingualism and the South African constitution. In S Makoni, G Smithermann, A Ball \& A Spears (Eds), Black linguistics: language, society and politics in Africa and the Americas. London: Routledge. 132-149.

MAKONI, S \& A PENNYCOOK (Eds). 2007. Disinventing and reconstituting languages. Clevedon, UK: Multilingual Matters.

MCGINLEY, W. 1992. The role of reading and writing while composing from sources. International Reading Association, 27(3):226-248.

MIDDENDORF, M. 1992. Bakhtin and the dialogic writing class. Journal of Basic Writing, $11(1): 34-47$.

MIGNOLO, W. 2000. Local histories/global designs: coloniality, subaltern knowledges, and border thinking. Princeton, NJ: Princeton University Press.

NORTON, B. 2014. Introduction: The Millennium Development Goals and multilingual literacy in African communities. Journal of Multilingual and Multicultural Development, 35(7):633-645. 
PFEIFFER, V. 2015. An investigation of L2 expressive writing in a tertiary institution in the Western Cape. Unpublished PhD thesis. University of the Western Cape.

PRATT, ML. 1991. Arts of the contact zone. Profession, 91:33-40.

SHOHAMY, E. 2006. Language policy: hidden agendas and new approaches. London: Routledge.

SUN PARK, M. 2013. Code-switching and translanguaging: potential functions in multilingual classrooms. Teachers College, Columbia University Working Papers in TESOL and Applied Linguistics, 13(2):50-52.

TRIBBLE, C. 1996. Writing. In CN Candlin \& HG Widdowson (Eds), Language teaching: a scheme for teacher education. Oxford: Oxford University Press.

VAN DER WALT, C. 2016. Reconsidering the role of language-in-education policies in multilingual higher education contexts1. Stellenbosch Papers in Linguistics Plus, 49:85104.

VAN DER WALT, C \& J DORNBRACK. 2011. Academic biliteracy in South African higher education: strategies and practices of successful students. Language, Cultural and Curriculum, 24(1):89-104.

VELASCO, P \& O GARCIA. 2014. Translanguaging and the writing of bilingual learners. Bilingual Research Journal, 37(1):6-23.

VIVIAN, B \& R FOURIE. 2016. Non-curricular postgraduate writing interventions at South African universities. Journal for Language Teaching, 50(1):145-165.

WEI, L. 2011. Moment analysis and translanguaging space: discursive construction of identities by multilingual Chinese youth in Britain. Journal of Pragmatics, 43:12221235.

WILLIAMS, C. 2002. Extending bilingualism in the education system. Available from http://www.assemblywales.org/3c91c7af00023d820000595000000000.pdf [Accessed:1 October 2018 ].

\section{BIOGRAPHICAL NOTES}

Verbra Pfeiffer is a research associate in the Curriculum Studies Department at Stellenbosch University. She has been a second and foreign language educator for eighteen years and taught English at every grade level ranging from preschool to university including language centres. Her research interests include academic literacy pedagogy, academic writing, second language advocacy and literature-based language pedagogy. Email: vfpfeiffer@sun.ac.za

Christa van der Walt is a professor and NRF-rated researcher in the Department of Curriculum Studies at Stellenbosch University. Her field of expertise is multilingual higher education. She is the author and co-author of multiple books, amongst others the soleauthored book Multilingual Higher Education: Beyond English-medium Orientations, published in 2013 by Multilingual Matters. Email: cvdwalt@sun.ac.za 